\title{
Mixture toxicity of six pharmaceuticals towards Aliivibrio fischeri, Daphnia magna, and Lemna minor
}

\author{
Anna Białk-Bielińska ${ }^{1}$ - Łukasz Grabarczyk ${ }^{1}$ - Ewa Mulkiewicz ${ }^{1}$ (D) - Alan Puckowski ${ }^{1} \cdot$ Stefan Stolte $^{2}$. \\ Piotr Stepnowski ${ }^{1}$
}

Received: 30 April 2021 / Accepted: 30 November 2021 / Published online: 14 December 2021

(c) The Author(s) 2021

\begin{abstract}
As the knowledge on the joint effects of pharmaceuticals towards different non-target organisms is still limited, the aim of our study was to evaluate the toxicity of mixtures of pharmaceuticals, as well as their baseline toxicity towards three selected organisms, namely the bioluminescent bacteria Aliivibrio fischeri, the crustacean Daphnia magna, and the duckweed Lemna minor. Different mixtures composed of three up to five pharmaceuticals having the same or different mechanisms of action in terms of their therapeutic activity (non-steroidal anti-inflammatory drugs, opioid analgesic, antibacterial and anti-epileptic drugs) were investigated. The observed $\mathrm{EC}_{50} \mathrm{~s}$ were compared with those predicted using the concentration addition (CA) and independent action (IA) models. In general, the $\mathrm{EC}_{50}$ values for mixtures predicted with the $\mathrm{CA}$ model were lower than those obtained with the IA model, although, in some cases, test predictions of these two models were almost identical. Most of the experimentally determined $\mathrm{EC}_{50}$ values for the specific mixtures were slightly higher than those predicted with the CA model; hence, a less than additive effect was noted. Based on the obtained results, it might be concluded that the CA model assumes the worst-case scenario and gives overall closer predictions; therefore, it should be recommended also for modeling the mixture toxicity of pharmaceuticals with different modes of action.
\end{abstract}

Keywords Emerging pollutants $\cdot$ Joint effects $\cdot$ Ecotoxicity $\cdot$ Aquatic environment $\cdot$ Toxicity test $\cdot$ Concentration addition · Independent action

\section{Introduction}

During the last decades, the problem of the presence of residues of pharmaceuticals (recognized as emerging pollutants) in the environment has gained huge scientific attention (Ankley et al. 2007; Kümmerer, 2010; Rodriguez-Mozaz et al. 2010; aus der Beek et al. 2016; Klatte et al. 2017; Pereira et al. 2020; Vasilachi et al. 2021). Since the first detection of pharmaceuticals in environmental samples, numerous studies related to this issue have been published. These include

Responsible Editor: Bruno Nunes

Ewa Mulkiewicz

ewa.mulkiewicz@ug.edu.pl

1 Department of Environmental Analysis, Faculty of Chemistry, University of Gdańsk, ul. Wita Stwosza 63, 80-308 Gdańsk, Poland

2 Institute of Water Chemistry, Technische Universität Dresden, 01062 Dresden, Germany the development of very selective and sensitive analytical procedures (Zrnčić et al. 2014), the application of different methods for their removal from a variety of environmental samples (Caban and Stepnowski 2021), and the evaluation of their fate and possible effects (Kümmerer, 2010; Brausch et al. 2012). Even though the state of knowledge on this topic has significantly improved, the potential threats posed by the presence of pharmaceuticals are still not sufficiently recognized.

Currently, the Environmental Risk Assessment (ERA) of pharmaceuticals is mainly carried out for individual substances (CHMP 2006; CVMP 2008; VICH 2000, 2005). However, they are present in the environment in different mixtures. For example, in the recently published report of German Environment Agency (Dusi et al. 2019) based on the data presented in 504 peer-reviewed articles published in 2010-2016, 771 pharmaceutical substances were detected in 75 countries worldwide. This proves how complex is the problem of the presence of the mixtures of pharmaceuticals in the environment. Godoy and Kummrov (2017) in 
the review paper that presents the summarized state of knowledge on the ecotoxicity of pharmaceuticals and personal care product mixtures based on the 194 assessments of the toxicity of mixtures from 65 articles published during 2000-2017. The authors also highlight future needs and indicate trends for performing such mixture studies.

Published ecotoxicological data prove that mixture effects of different pharmaceuticals towards non-target organisms may be higher than those predicted on the basis of the single components toxicity data (e.g. Cleuvers 2003; Eguchi et al. 2004; Drzymała and Kalka 2020). Although the results of studies on the mixture toxicity of pharmaceuticals are available (Table 1), new research on this subject may contribute to improve our understanding of the consequences of their presence in the environment. In Table 1, selected available literature data on the toxicity of mixtures of pharmaceuticals towards aquatic organisms representing three selected in our study tropic levels (bacteria, higher plants, or crustacean) mainly referring to standard endpoints in acute toxicity tests are presented.

For all the abovementioned reasons, more ecotoxicological studies evaluating the joint effects of pharmaceuticals on non-target organisms are required. The need for a more realistic ERA of pharmaceuticals has been identified by other scientists (Schmitt et al. 2010; Tarazona et al. 2010; Backhaus 2016).

Taking into consideration the number of possible variations of mixtures present in the environment, estimating the effects of mixtures from individual substance data is generally accepted. The application of modeling to assess mixture toxicity is the most common and best-suited approach (Kortenkamp 2009). In general, two different models-CA, concentration addition and IA, independent action-have been proposed to predict the toxicity of mixtures of substances with similar and different modes of action, respectively (Kortenkamp et al. 2009) and have been described in detail in the "Materials and methods" section. However, it must also be highlighted that there is a third mixture assessment method, which includes interactions between chemicals in the mixture, and refers to all joint effects (such as synergism or antagonism) that deviate from the concept of additivity. Nevertheless, based on the information presented in the Bopp et al. (2015) report, interactions at environmentally relevant concentrations (which are usually quite low) are rare and, if observed, they show deviation from CA predictions that are in general relatively small.

The main aim of our study was to evaluate the toxicity of different mixtures of pharmaceuticals belonging to different therapeutic groups (Table 2), hence presenting different modes of action. The toxicity towards three selected organisms, namely, the bioluminescent bacteria Aliivibrio fischeri (formerly known as Vibrio fischeri), the crustacean Daphnia magna, and the duckweed Lemna minor was evaluated. The selection of pharmaceuticals and tested species was based on our previously published results revealing their toxicity towards these organisms (Grabarczyk et al. 2020). Detailed justification of selection of these specific pharmaceuticals can be also found in that paper; however, it must be at least highlighted that they belong to the most frequently consumed and detected drugs in environmental samples. Therefore, we considered it crucial to also investigate their joint effects. Moreover, pharmaceuticals are designed to be biologically active; however, in non-target organisms, they may act in a specific or non-specific (as baseline toxicants) way. It is already known, for example, that estrogens (due to their specific mode of action) have a negative effect on fish (Kidd et al. 2007). The antidepressant fluoxetine, in turn, by affecting the biosynthetic pathways involved in the production of energy in algae, acts through a different (unpredicted) specific mode of toxic action (Neuwoehner et al. 2009; Escher et al. 2011). Therefore, in order to determine whether the selected pharmaceuticals act as baseline toxicants in the standard acute test, the toxic ratio values were calculated. The investigated mixtures were composed of pharmaceuticals belonging to the same therapeutic group as well as those with different modes of action in order to evaluate the applicability of the CA and IA models for the prediction of their joint toxic effects.

\section{Materials and methods}

\section{Chemicals}

The pharmaceuticals and all reagents were purchased from Sigma-Aldrich (Steinheim, Germany). Pharmaceutical solutions were prepared immediately before the test in appropriate test medium. However, due to different water solubility, the stock solutions of CRB, SMZ, NAP, and IBU were prepared firstly in acetone at a concentration of $10 \mathrm{mg} \mathrm{mL}^{-1}$ and then diluted before the test in the proper test medium, so that the organic modifier content was not higher than $1 \%$ in the tested samples. On the contrary, DIC-sodium salt and TRA were always freshly prepared directly in the test medium due to their good solubility in water. Moreover, solvent controls were investigated in each test in order to verify that the addition of an organic solvent did not cause any effects.

\section{Investigated pharmaceutical mixtures}

Nine different mixtures were tested with regard to the selected organisms (Table 3). The composition of each mixture was established based on the results obtained for single compounds, which were recently published by Grabarczyk et al. (2020). In general, in the mixture experiments, only pharmaceuticals with a determined $\mathrm{EC}_{50}$ 


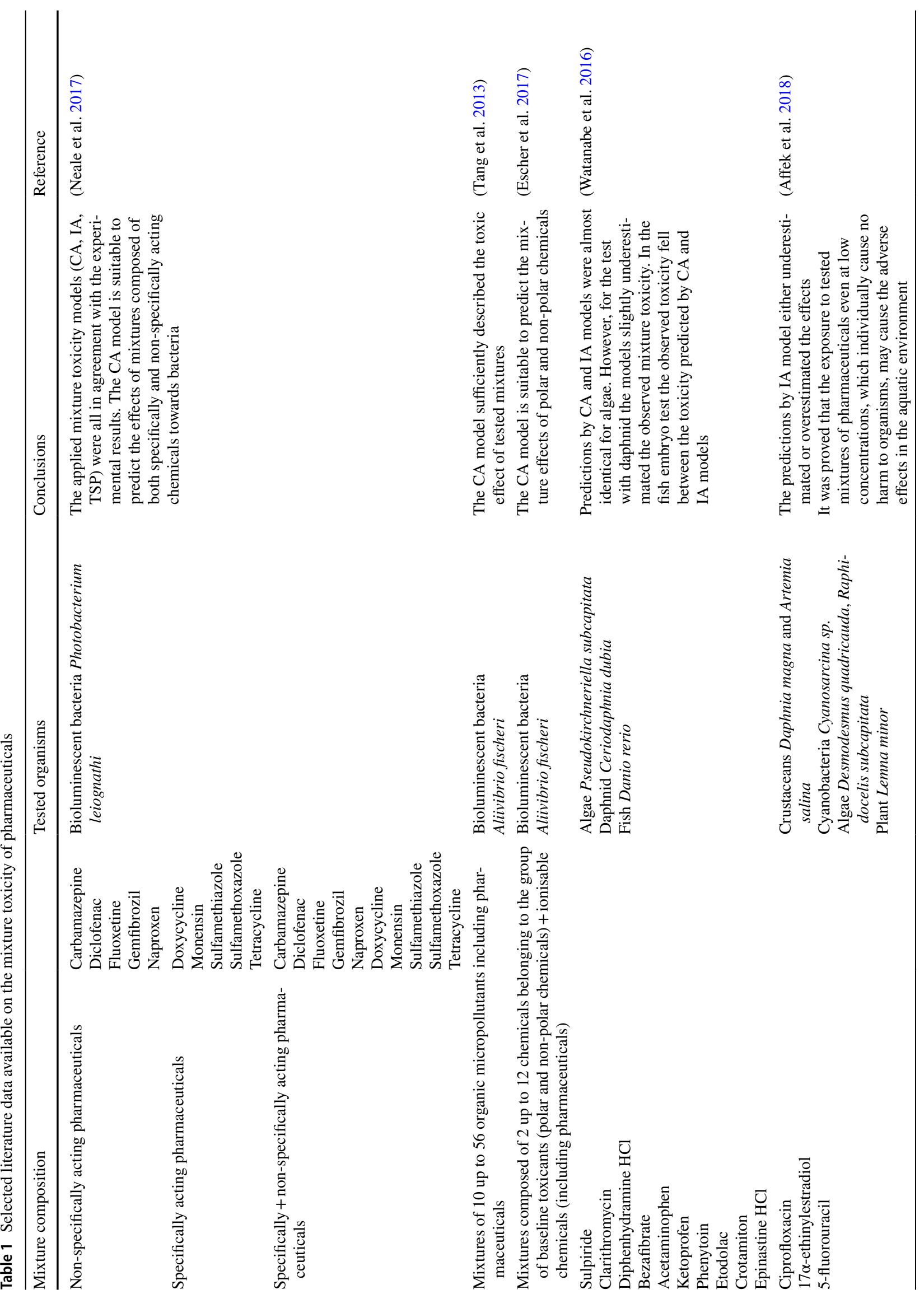




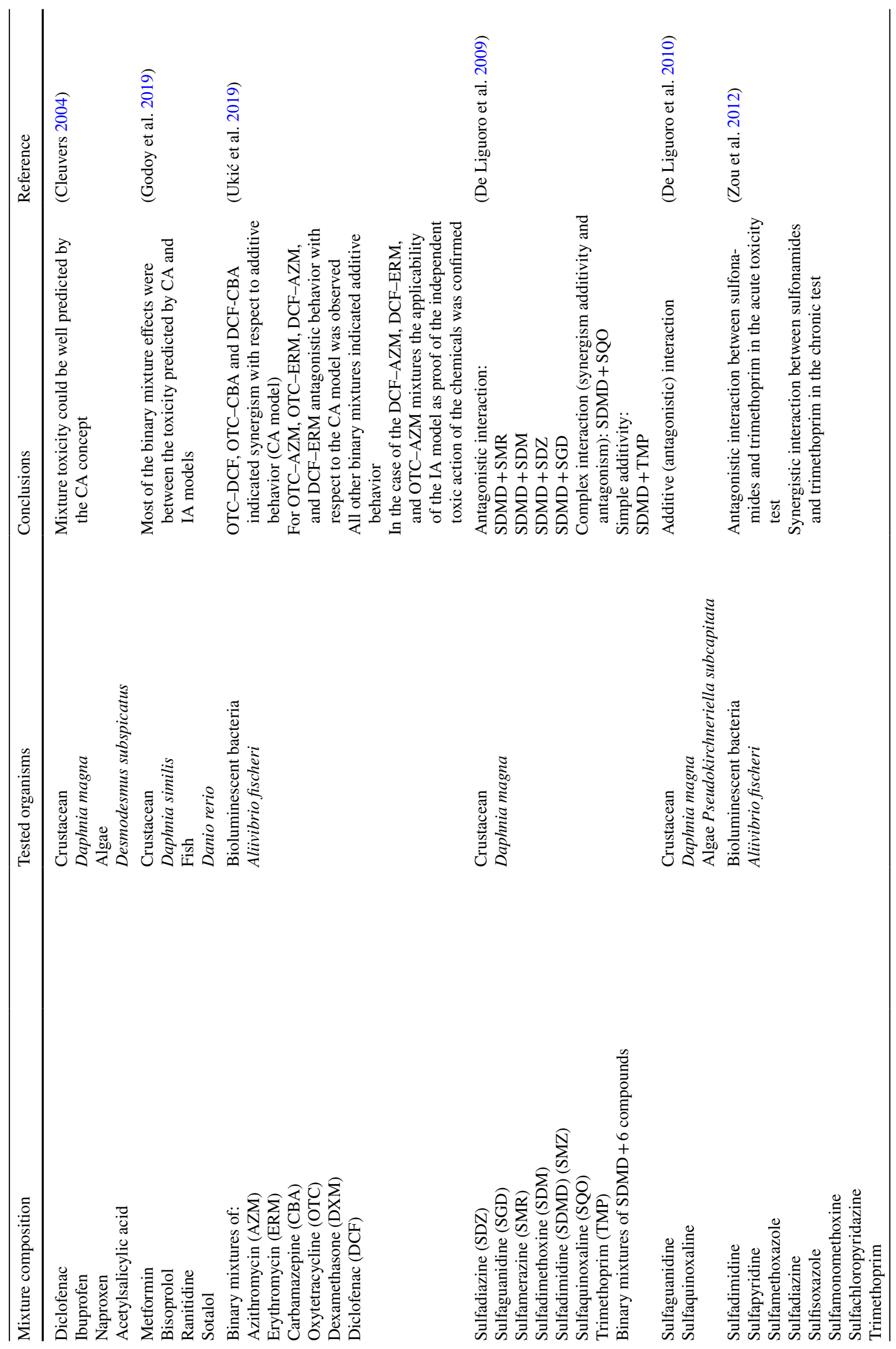




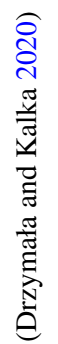
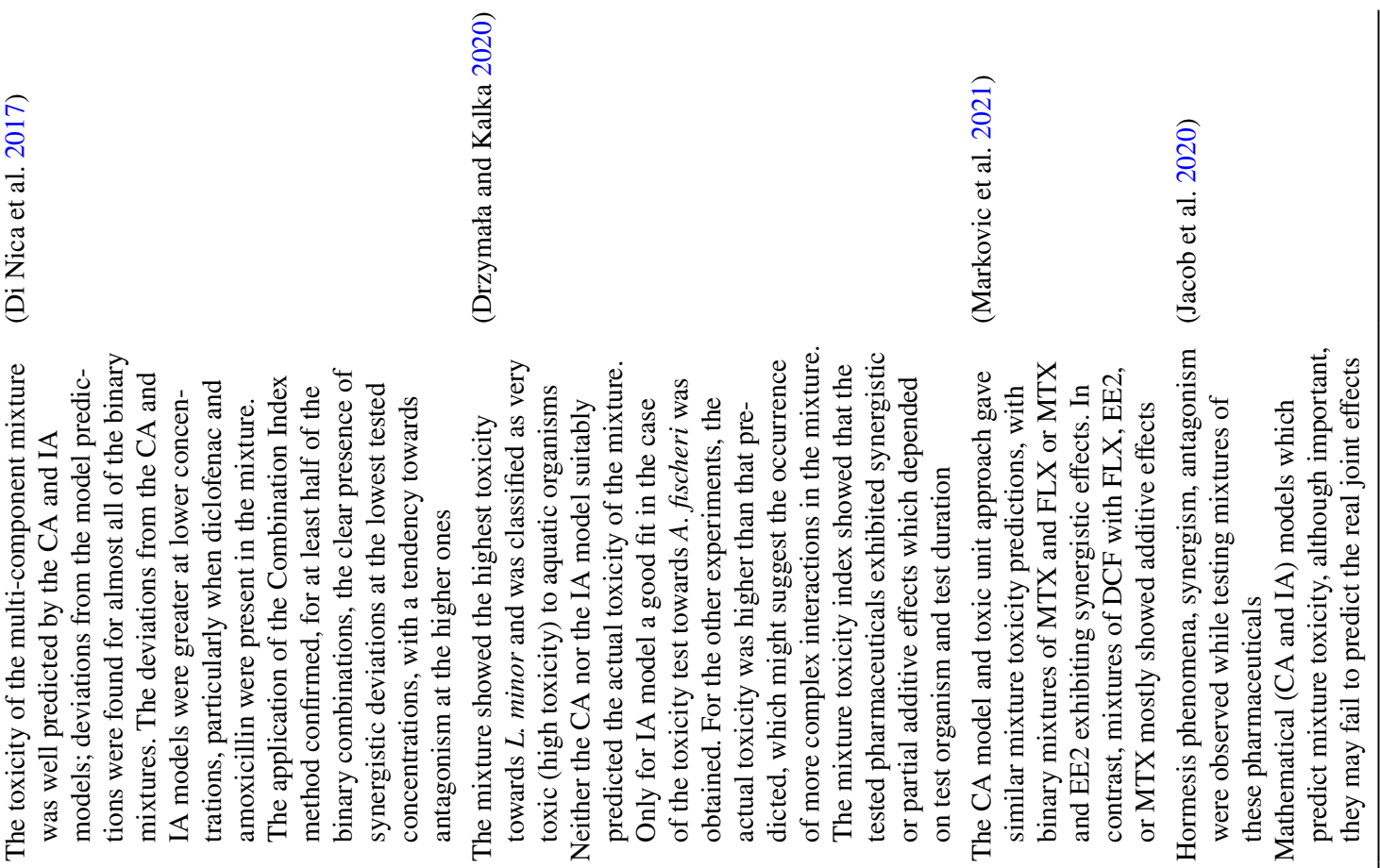

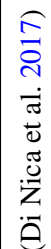

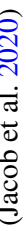

$$
\text { 产 }
$$

\section{离}

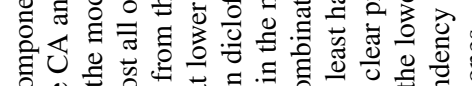

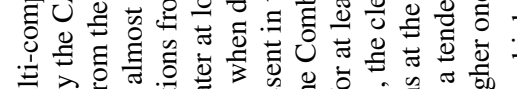

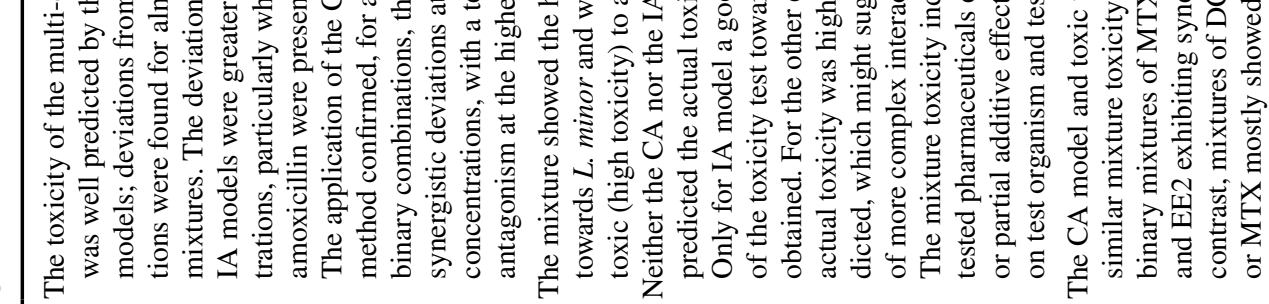
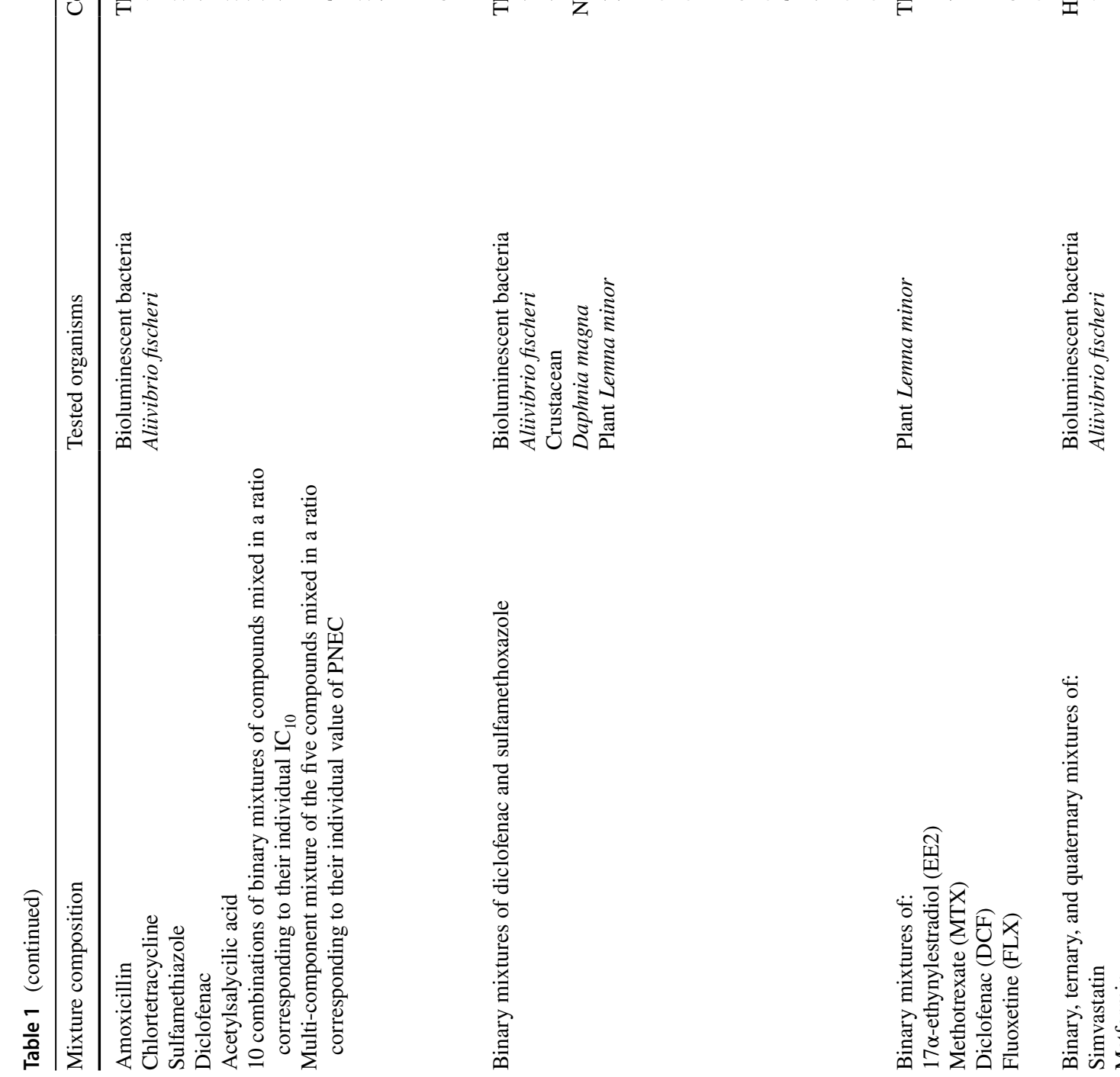

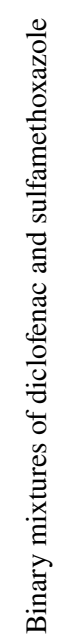

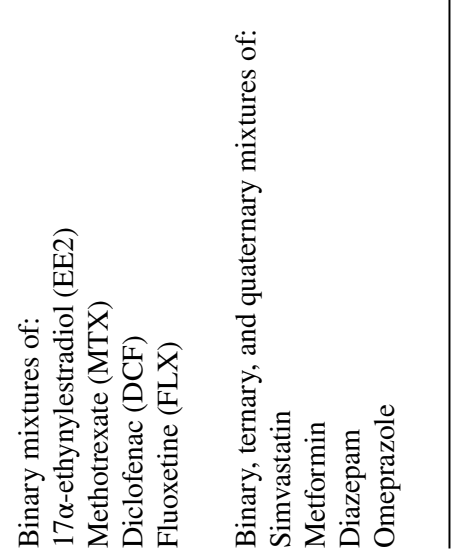


Table 2 Investigated pharmaceuticals

\begin{tabular}{|c|c|c|}
\hline Therapeutic group & $\begin{array}{c}\text { Name } \\
\text { (abbreviation) } \\
\text { [CAS number] }\end{array}$ & Chemical structure \\
\hline \multirow{3}{*}{$\begin{array}{l}\text { Non-steroidal Anti- } \\
\text { inflammatory Drugs } \\
\text { (NSAIDs) }\end{array}$} & $\begin{array}{c}\text { Diclofenac } \\
(\mathrm{DIC}) \\
{[15307-79-6]}\end{array}$ & \\
\hline & $\begin{array}{c}\text { Ibuprofen } \\
\text { (IBU) } \\
{[15687-27-1]}\end{array}$ & \\
\hline & $\begin{array}{c}\text { Naproxen } \\
\text { (NAP) } \\
{[22204-53-1]}\end{array}$ & \\
\hline Opioid analgesic & $\begin{array}{c}\text { Tramadol } \\
\text { (TRA) } \\
{[36282-47-0]}\end{array}$ & \\
\hline Antibacterial drugs & $\begin{array}{c}\text { Sulfamethoxazole } \\
\text { (SMZ) } \\
{[723-46-6]}\end{array}$ & \\
\hline Anti-epileptic drugs & $\begin{array}{c}\text { Carbamazepine } \\
\text { (CRB) } \\
{[298-46-4]}\end{array}$ & \\
\hline
\end{tabular}

values were investigated, as those with an $\mathrm{EC}_{50}$ assessed as higher than $100 \mathrm{mg} \mathrm{L}^{-1}$ according to the EC-Directive 93/67/EEC (European Commission 1993) are not considered to be harmful to aquatic organisms. Therefore, mixtures consisting of:

- DIC, IBU, NAP, and SMZ were tested towards A. fischeri;

- DIC, IBU, NAP, SMZ, and TRA were tested towards D. magna;

- DIC, IBU, NAP, SMZ, and CRB were tested towards L. minor.

Stock solutions of each mixture were prepared and the tests were performed in a series of dilutions to achieve full dose-response curves. The mixture concentrations ranged from 3.125 up to $100 \mathrm{mg} \mathrm{L}^{-1}$ for the tests with L. minor, from 1 up to $50 \mathrm{mg} \mathrm{L}^{-1}$ for the tests with $A$. fischeri, and from 20 up to $100 \mathrm{mg} \mathrm{L}^{-1}$ for the tests with D. magna.

It must be highlighted that the mixture studies were performed immediately after experiments evaluating the toxicity of single compounds in order to obtain reliable results. The fraction of the individual pharmaceutical in the specific mixture was determined based on the $\mathrm{EC}_{50}$ values for single pharmaceuticals and the CA model, which is presented in Table 3.

\section{Ecotoxicological tests}

All the ecotoxicological tests were carried out according to the recommended OECD or ISO guidelines. In order to check the test procedure and validity of the test reference substances (3,5-dichlorophenol in the tests with $L$. minor, potassium dichromate in the tests with A. fischeri and $D$. magna) were tested at least twice during the test time period. Each of the tests was performed in two or more 
Table 3 Single toxicity and the fraction of each chemical used in the different tested mixtures (mixtures were prepared by following an equi-toxicity concentration ratio design)

\begin{tabular}{|c|c|c|c|c|c|c|c|c|}
\hline Organism & Mixture symbol & DIC & IBU & NAP & SMZ & CRB & TRA & $\Sigma / \mathrm{EC}_{50}, \mathrm{CA}$ \\
\hline \multirow[t]{3}{*}{ A. fischeri } & $\begin{array}{l}\text { Single toxicity } \mathbf{E C}_{50} \\
{\left[\mathrm{mg} \mathrm{L} \mathrm{L}^{-1}\right]^{a}}\end{array}$ & 11.62 & 14.97 & 25.17 & 51.77 & $>100$ & $>100$ & \\
\hline & $\mathrm{M} 1\left[\mathrm{mg} \mathrm{L}^{-1}\right]$ & 3.83 & 4.94 & 8.31 & & & & 17.08 \\
\hline & $\mathrm{M} 2\left[\mathrm{mg} \mathrm{L}^{-1}\right]$ & 2.91 & 3.74 & 6.29 & 12.94 & & & 25.88 \\
\hline \multirow[t]{3}{*}{ D. magna } & $\begin{array}{l}\text { Single toxicity } \mathbf{E C}_{50} \\
{\left[\mathrm{mg} \mathrm{L}^{-1}\right]^{a}}\end{array}$ & 59.09 & 50.07 & 74.39 & 42.74 & $>100$ & 69.69 & \\
\hline & M1 $\left[\mathrm{mg} \mathrm{L}^{-1}\right]$ & 19.50 & 16.52 & 24.55 & & & & 60.57 \\
\hline & $\mathrm{M} 2\left[\mathrm{mg} \mathrm{L}^{-1}\right]$ & 11.82 & 10.01 & 14.88 & 8.55 & & 13.94 & 59.20 \\
\hline \multirow[t]{6}{*}{ L. minor } & $\begin{array}{l}\text { Single toxicity } \mathbf{E C}_{50} \\
{\left[\mathrm{mg} \mathrm{L}^{-1}\right]^{a}}\end{array}$ & 16.52 & 13.25 & 20.70 & 3.07 & 50.17 & $>100$ & \\
\hline & $\mathrm{M} 1\left[\mathrm{mg} \mathrm{L}^{-1}\right]$ & 5.45 & 4.37 & 6.83 & & & & 16.65 \\
\hline & $\mathrm{M} 2\left[\mathrm{mg} \mathrm{L}^{-1}\right]$ & 3.30 & 2.65 & 4.14 & 0.61 & 10.03 & & 20.73 \\
\hline & $\mathrm{M} 3\left[\mathrm{mg} \mathrm{L}^{-1}\right]$ & & 4.37 & & 1.01 & 16.56 & & 21.94 \\
\hline & $\mathrm{M} 4\left[\mathrm{mg} \mathrm{L}^{-1}\right]$ & 4.13 & 3.31 & 5.17 & 0.77 & & & 13.38 \\
\hline & $\mathrm{M5}\left[\mathrm{mg} \mathrm{L}^{-1}\right]$ & 4.13 & 3.31 & 5.17 & & 12.54 & & 25.15 \\
\hline
\end{tabular}

${ }^{a}$ Data incorporated from our previous study (Grabarczyk et al. 2020) independent replicates. The exact number of replicates and concentrations tested within each test is described below. The dose-response curves and the $\mathrm{EC}_{50}$ values of the investigated mixtures were obtained using the drfit package in the $\mathrm{R}$ language and environment for statistical computing (http://www.r-project.org) (R Core Team, 2014). The mathematical formulas applied for this purpose are presented and described in the Supplementary Material.

\section{Aliivibrio fischeri}

The luminescence inhibition assay was performed according to the ISO11348-3:2007 guideline (2007) using the LCK 482 test kit (Dr. Lange GmbH, Germany). A detailed description of this test is presented in our previous paper (Grabarczyk et al. 2020). Briefly, the test was performed at $15^{\circ} \mathrm{C}$. The $\mathrm{pH}$ of the test medium and tested solutions was 7 . The bioluminescence inhibition was measured after $30 \mathrm{~min}$. Each test consisted of a control (including solvent controls) and eight different concentrations $(1,2.5,5,10,20,30,40$, and $50 \mathrm{mg} \mathrm{L}^{-1}$ ) of the investigated mixtures (M1 and M2) in two replicates.

\section{Daphnia magna}

The acute immobilization test with D. magna was carried out using DAPHTOXKIT F (MicroBioTest Incorporation, Gent, Belgium), which was performed based on the OECD 202 guideline (OECD 202, 2004). All the details of this test are presented in our previous paper (Garbarczyk et al. 2020). Briefly, the test was performed for $48 \mathrm{~h}$ at $20^{\circ} \mathrm{C}\left( \pm 1^{\circ} \mathrm{C}\right)$ in the darkness and the $\mathrm{pH}$ of the medium was kept within a range of 6 to 8. Each test consisted of a control (including solvent controls) and five different concentrations (20,40, 60,80 , and $100 \mathrm{mg} \mathrm{L}^{-1}$ ) of the investigated mixtures (M1 and M2) in four replicates.

\section{Lemna minor}

The $L$. minor growth inhibition test (7 days) was performed in accordance with the OECD 221 guideline (OECD 221, 2006) and is described in detail in our previous paper (Grabarczyk et al. 2020). Briefly, the test was performed in a climate chamber at $25{ }^{\circ} \mathrm{C}\left( \pm 1{ }^{\circ} \mathrm{C}\right)$ under irradiation of $6000 \mathrm{~lx}$ and with a humidity of $60 \%$. The $\mathrm{pH}$ value of the test medium and all tested solutions was $5.5( \pm 0.5)$. Every test included six different concentrations (3.125, $6.25,12.5,25,50$, and $100 \mathrm{mg} \mathrm{L}^{-1}$ ) of each mixture tested (M1-M5) in three replicates, six controls, and six solvent controls.

\section{Applied models}

The applied models for predicting the mixture toxicity, as well as to determine the baseline toxicity of investigated pharmaceuticals, are presented and described in Table 4. To calculate $\mathrm{EC}_{50}$ (IA), the experimental $\mathrm{EC}_{50}$ values for the single substances and the calculated percentage of the individual components in the mixture (Table 3 ) were used. Then, the concentrations of individual components of the mixture were determined so that the effects caused by them, calculated in the $\mathrm{R}$ program and substituted for the equation given in Table 4, would give the value $E\left(c_{\text {mix }}\right)$ equal to 0.5 . The concentrations of individual components of the mixture and the effects caused by them calculated in the $\mathrm{R}$ program are presented in Table $4 \mathrm{~S}$. 


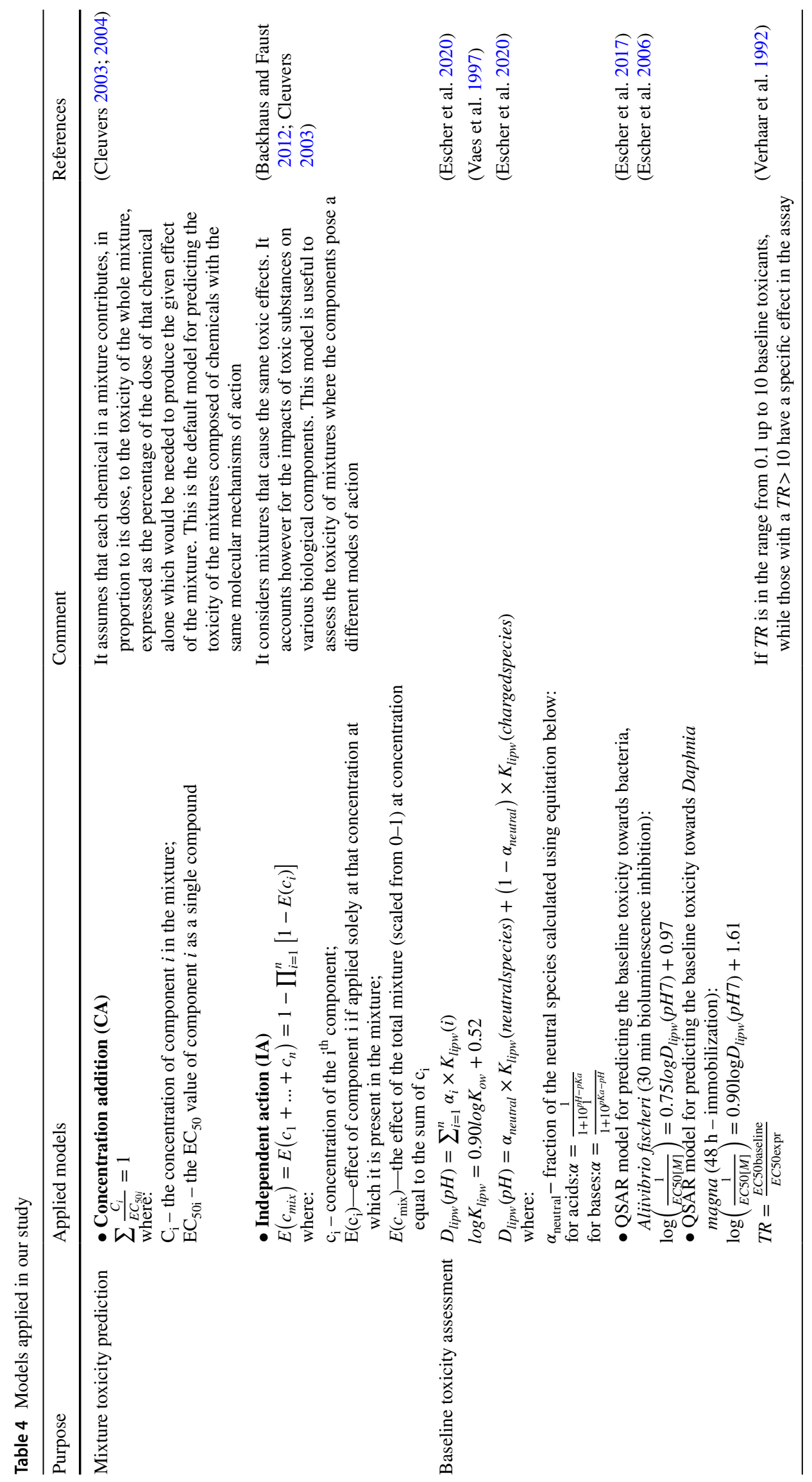


The accuracy of the CA model predictions was verified by the application of the the model deviation ratio (MDR) approach (Belden et al. 2007; Markovic et al. 2021). This factor was calculated by dividing the predicted effective concentration $\left(\mathrm{EC}_{50}\right)$ by the experimentally observed effective concentration of the mixture for the $50 \%$ effect. In order to determine if a pharmaceutical acts as baseline toxicant (act via non-specific effect) or had a specific effect in the whole organism, the experimental $\mathrm{EC}_{50}$ values obtained for individual compounds were compared with those predicted using QSARs models-available in the literature (Escher et al. 2006; 2017) for baseline toxicity. As for L. minor, such QSAR models are not available; this procedure was applied for A. fischeri and D. magna. It must be highlighted that most of the baseline QSAR models were developed for inert organic molecules and are based on the octanol-water partition coefficient $\left(K_{\text {ow }}\right)$ used as the descriptor of hydrophobicity. However, pharmaceuticals are in general ionizable compounds (classified as weak acids or bases) (Tarazona et al. 2010), and in their case, application of $K_{\text {ow }}$ coefficient is unsuitable to measure bioaccumulation on biomembranes (recognized as the target site for non-specifically acting narcotic/baseline toxicants). For this purpose, the $K_{\text {ow }}$ was replaced by the liposome-water distribution coefficient at a defined $\mathrm{pH}$ value (e.g. $D_{\text {lipw }}(\mathrm{pH} 7)$ ), which is determined using the equitation in Table 4 and is considered to be better descriptor (Escher et al. 2011). However, as hydrophobicity of a specific chemical, as well as its charge and interactions with the membrane, is crucial in partitioning into membranes, the $D_{\text {lipw }}(\mathrm{pH} 7)$ parameter takes into account the speciation of organic acids and bases at pH 7 (Escher et al. 2020, 2011). If the experimental $D_{\text {lipw }}(\mathrm{pH} 7)$ is not available in the literature, it can be calculated based on the value of the liposome-water partition coefficient of the neutral species $\left(K_{\text {lipw }}\right)$ and speciation based on the acidity constant (pKa). If $K_{\text {lipw }}$ is not available, it can be calculated based on the $K_{\text {ow }}$ value. For this purpose, we have gathered the literature data, and for missing information, we have performed proper calculations by applying the adequate equations and QSAR models, presented in the Table 4. In our study, we have applied the QSAR models for ionisable organic chemicals, which have been rescaled from the original QSAR models (based on $\log K_{\text {ow }}$ ) and are recommended by Escher et al. (2020). The determined $\mathrm{EC}_{50}$ values (based on these QSAR models) can be applied to identify whether specific compound (pharmaceutical) acts as a narcotic/baseline toxicant as well as to determine its specific toxicity level (expressed by the $T R$ (toxic ratio) value-Table 4).

\section{Results and discussion}

The determined experimental $\mathrm{EC}_{50}$ values for the investigated mixtures of pharmaceuticals, as well as their $\mathrm{EC}_{50}$ values predicted using the $\mathrm{CA}$ and IA models, are presented in Table 5. All obtained dose-response curves, as well as specific parameters describing dose-response curves, are presented in Figs. 1S-3S and in Tables 1S-3S in the Supplementary Material.

The investigated mixtures were composed of pharmaceuticals belonging to the same therapeutic group (e.g. M1 in each test) as well as those with different modes of action (M2 in the A. fischeri and D. magna tests and M2-M5 in the $L$. minor test) in order to evaluate the applicability of the CA and IA models for the prediction of their joint toxic effects.

However, in order to determine whether the selected pharmaceuticals act as baseline toxicants in the standard acute test, the $T R$ values were calculated. In general, it is believed that baseline toxicity (narcosis) results from of the non-specific disturbance of the integrity and functioning of biological cell membranes by chemicals (mostly organic pollutants) by partitioning into these membranes (Escher et al. 2011). As these pollutants are not bound covalently to the membrane, this baseline toxicity is a reversible mechanism. Escher et al. (2011) highlighted that membrane disturbance is usually caused by the accumulation of specific pollutant in hydrophobic phases (like membrane lipids) within the organism; however, other mechanisms such as specific protein interactions cannot be excluded.

Based on the data presented in Table 6, it can be concluded that all pharmaceuticals acted specifically $(T R>10)$ in the test with A. fischeri, taking into account the new, quite recently rescaled QSAR model (Escher et al. 2017). However, different observations were made in the test with D. magna. The pharmaceuticals belonging to the group of non-steroidal anti-inflammatory drugs (NSAIDs), including DIC, IBU, and NAP, could be classified as baseline toxicants (determined $T R$ values $<10$ ). On the other hand, $T R$ values exceeding 10 obtained for SMZ and TRA (60.2 and 22.3, respectively) indicated specific toxicity, which is in agreement with the results of the study of Escher et al. (2011). Moreover, the highest values of TR in the A. fischeri and D. magna tests proved that SMZ was the most specifically acting pharmaceutical, which was also observed by other authors who evaluated their toxicity in tests with other luminescence bacteria Photobacterium leiognathi (Neale et al. 2017) or green algae Pseudokirchneriella subcapitata (Escher et al. 2011).

In general, it is commonly accepted that mixtures composed of chemicals with the same mode of action act according to the CA model. On the other hand, if all components 
Table 5 Predicted vs. experimental $\mathrm{EC}_{50}\left[\mathrm{mg} \mathrm{L}^{-1}\right]$ values of the investigated mixtures

\begin{tabular}{|c|c|c|c|c|c|c|}
\hline Organism & Mixture & $\mathrm{EC}_{50}(\mathrm{CA})$ & $\mathrm{EC}_{50}(\mathrm{IA})$ & $\begin{array}{l}\mathrm{EC}_{50} \text { expr } \\
\text { (confidence interval) }\end{array}$ & MDR & Effect* \\
\hline \multirow[t]{2}{*}{ A. fischeri } & $\begin{array}{l}\text { M1 } \\
\text { (DIC, IBU, NAP) }\end{array}$ & 17.08 & 17.59 & $\begin{array}{c}17.97 \\
(17.35-18.63)\end{array}$ & 1.0 & $\mathrm{ad}$ \\
\hline & $\begin{array}{l}\text { M2 } \\
\text { (DIC, IBU, NAP, SMZ) }\end{array}$ & 25.88 & 31.87 & $\begin{array}{r}35.58 \\
(34.55-36.68)\end{array}$ & 0.7 & $\mathrm{ad}$ \\
\hline \multirow[t]{2}{*}{ D. magna } & $\begin{array}{l}\text { M1 } \\
\text { (DIC, IBU, NAP) }\end{array}$ & 60.57 & 135.52 & $\begin{array}{r}67.14 \\
(59.83-77.05)\end{array}$ & 0.9 & $\mathrm{ad}$ \\
\hline & $\begin{array}{l}\text { M2 } \\
\text { (DIC, IBU, NAP, SMZ, TRA) }\end{array}$ & 59.20 & 187.64 & $\begin{array}{c}92.39 \\
(84.31-107.33)\end{array}$ & 0.6 & $\mathrm{a}$ \\
\hline \multirow[t]{5}{*}{ L. minor } & $\begin{array}{l}\text { M1 } \\
\text { (DIC, IBU, NAP) }\end{array}$ & 16.65 & 29.62 & $\begin{array}{r}10.35 \\
(8.98-11.86)\end{array}$ & 1.6 & $\mathrm{~s}$ \\
\hline & $\begin{array}{l}\text { M2 } \\
\text { (DIC, IBU, NAP, SMZ, CRB) }\end{array}$ & 20.73 & 30.77 & $\begin{array}{r}21.39 \\
(18.10-25.02)\end{array}$ & 1.0 & $\mathrm{ad}$ \\
\hline & $\begin{array}{l}\text { M3 } \\
\text { (IBU, SMZ, CRB) }\end{array}$ & 21.94 & 21.95 & $\begin{array}{r}23.30 \\
(20.81-26.06)\end{array}$ & 0.9 & $\mathrm{ad}$ \\
\hline & $\begin{array}{l}\text { M4 } \\
\text { (DIC, IBU, NAP, SMZ) }\end{array}$ & 13.38 & 20.40 & $\begin{array}{r}15.89 \\
(13.55-18.61)\end{array}$ & 0.8 & $\mathrm{ad}$ \\
\hline & $\begin{array}{l}\text { M5 } \\
\text { (DIC, IBU, NAP, CRB) }\end{array}$ & 25.15 & 40.39 & $\begin{array}{r}24.00 \\
(18.59-30.27)\end{array}$ & 1.0 & $\mathrm{ad}$ \\
\hline
\end{tabular}

MDR model deviation ratio, * effect of the mixture evaluated based on MDR, ad - additive, a - antagonistic, $\mathrm{s}$ - synergistic exhibit a different modes of action, the IA model should be applied (Altenburger et al. 2003). However, for practical purposes, the CA model is usually recognized as a realistic worst-case scenario as the predicted mixture toxicity is usually within an order of magnitude of the experimental results (Altenburger et al. 2004). Based on the available literature data, most of the mixture studies with pharmaceuticals generally confirmed that the CA model adequately predicts the toxicity of the mixtures of pharmaceuticals from the same and different therapeutic groups (Table 1).

Hermens and Leeuwangh (1982) suggested that for multicomponent mixtures consisting of chemicals posing different modes of action, where their individual concentrations are much below the individual toxic effect threshold, the underlying baseline toxicity may complement a substantial joint effect. Van Wezel and Opperhuizen (1995) stated that actually all chemicals exert a baseline toxicity, regardless of their specific mode of action. In complex mixtures with a defined toxicity, the number of constituents with different specific mechanisms of toxicity increases; however, the concentration of each chemical decreases. Therefore, their contribution to the overall toxicity by the non-specific baseline toxicity increases while that caused by the specific mode of toxic action decreases (Escher et al. 2011).

In most cases (except M1 in the A. fischeri test and M1 and M5 in the L. minor test), the experimentally determined $\mathrm{EC}_{50}$ values for the specific mixtures were slightly higher than those predicted with the CA model. Based on the obtained results, presented in Table 5, it can be noticed that the $\mathrm{EC}_{50}$ values predicted with the $\mathrm{CA}$ model were always lower than those obtained in the IA model. Therefore, it could be concluded that an additive or less than additive effect was noted. It was also confirmed by MDR analysis, which indicated additive toxicity (MDR value between 0.7 and 1.3) (Phyu et al. 2011) for most of the mixtures tested (Table 5). However, in some cases (mixture M1 and M2 in the A. fischeri test and M3 and M4 in the L. minor test), the CA and IA models gave very similar predictions (Table 5), which is quite common for mixtures of many compounds (Backhaus et al. 2000). This might result from the basic limitations of these two concepts, which may be correlated with the fact that they do not consider such factors as uptake, distribution, metabolism, and excretion of chemicals, which may have potential effects on the mixture toxicity.

The detected additive or less than additive interactions are in agreement with data from other authors (Brain et al. 2004; De Liguoro et al. 2009, 2010; Tang et al. 2013; Geiger et al. 2016; Escher et al. 2017; Neale et al. 2017). For example, Brain et al. (2004) observed that mixture toxicity of eight pharmaceuticals (belonging to different groups with different modes of action) to the aquatic macrophytes Lemna gibba and Myriophyllum sibiricum was additive. Moreover, De Liguoro et al. $(2009,2010)$ assessed that the toxicity of mixture of sulfamethazine with trimethoprim towards $D$. magna, as well as various binary mixtures of sulfonamides (sulfaquinoxaline and sulfaguanidine) towards $P$. subcapitata and $D$. magna, was less than additive.

On the other hand, Drzymała and Kalka (2020), who studied the toxicity of binary mixtures of two pharmaceuticals (diclofenac and sulfamethoxazole) belonging 


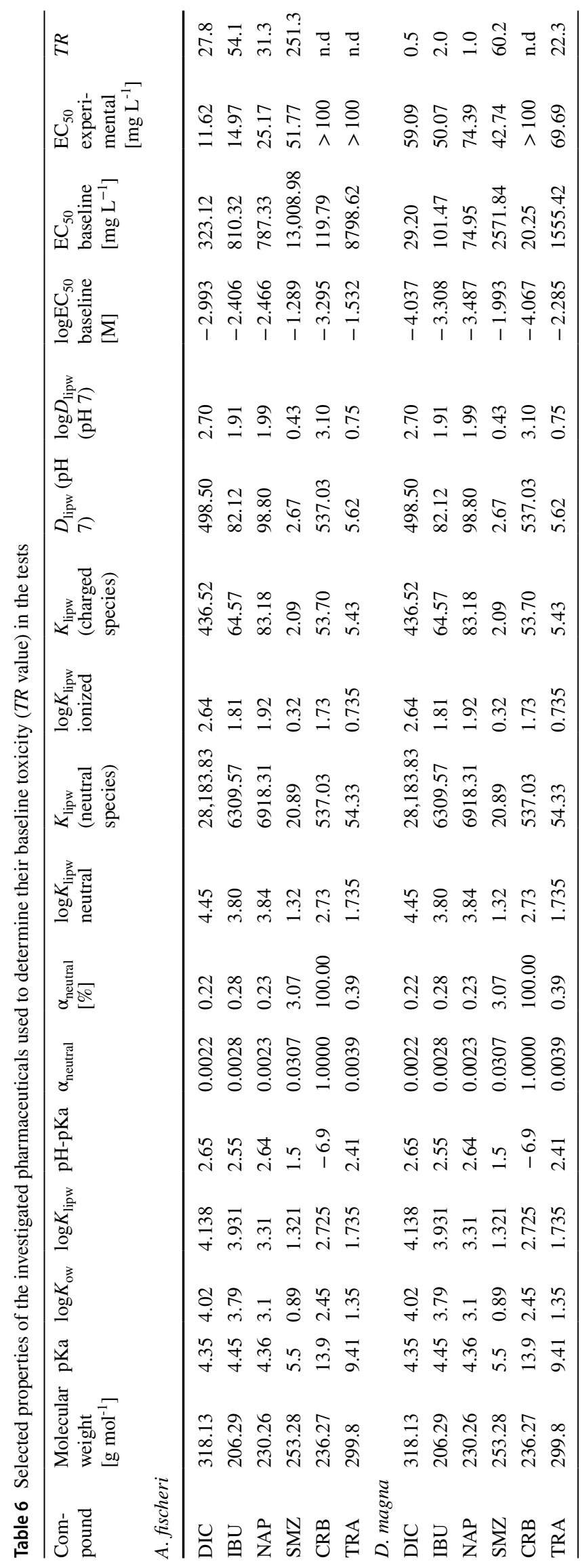


to different therapeutic groups, observed that none of the applied models (CA and IA) was suitable to predict the actual toxicity of the investigated mixtures. They have actually confirmed the interaction between mixture components, emphasizing that partial additive or even synergistic effects depended on the organisms tested and the duration of the test. Similarly, Markovic et al. (2021) observed that neither CA or IA models could predict the toxicity of the binary mixtures of methotrexate with $17 \alpha$-ethynylestradiol or fluoxetine to Lemna minor, with both models underestimating the effect. The model deviation ratio calculated for these two mixtures was greater than 1.3, suggested synergistic effects. In turn, in the same study, the CA model was found to be the best fit for the toxicity of the binary mixtures of diclofenac and $17 \alpha$-ethynylestradiol but slightly overestimated the toxicity of the mixtures of diclofenac with methotrexate or fluoxetine for which the predictions of the IA model were closer to the experimental results. However, MDR calculated for these two binary mixtures were greater than 0.7 , suggesting that the CA model is still appropriate (Markovic et al. 2021). MDR analysis was also additionally applied in this study to verify the accuracy of the CA model predictions. Based on obtained results, it might be concluded that the CA model is still the most appropriate one. Only in one case (M1 in the $L$. minor test), MDR value was greater than 1.3 indicating synergistic effect (Table 5).

Even though the IA model is the recommended concept to predict the toxicity of chemicals with different modes of action, in our study, the mixture effects of pharmaceuticals with different modes of action were well predicted by CA model. Therefore, it seems to be sufficiently precautionary to use the CA model as a default approach with a relatively small probability of underestimating the toxicity, as it usually predicts higher toxicity than IA model.

The choice can be relevant in terms of assessing the risk posed by the residues of pharmaceuticals in the environment. If the CA model can be assumed, the risk quotient for the mixture can be calculated as the sum of risk quotients for individual pharmaceuticals (Escher et al. 2011).

However, Godoy and Kummrov (2017) in their review paper, concerning the mixture toxicity testing of pharmaceuticals and personal care products, highlight that this is still a very complex challenge and understanding the mechanisms and interactions involved in the joint action of these compounds are on special concern. Moreover, it is also highlighted that in the future, consistent criteria for prioritizing mixture components, selection of the test type in terms of their time duration, endpoint and level of biological organization, and selection of the adequate tools to predict and assess the obtained data should be established (Godoy and Kummrov 2017).

\section{Conclusions}

A comparative report focused on the assessment of mixture toxicity of six pharmaceuticals belonging to different therapeutic groups towards the bacteria $A$. fischeri, the crustacean $D$. magna, and the duckweed L. minor has been presented for the first time. Mixture toxicity experiment was combined with the assessment of their mode of toxic action based on the application of appropriate QSAR models available for the test with A. fischeri and D. magna to determine whether the selected pharmaceuticals act as baseline toxicants in the standard acute test. Based on obtained results, it was concluded that all pharmaceuticals acted specifically $(T R>10)$ in the test with A. fischeri; however, different observations were made in the test with D. magna. The pharmaceuticals belonging to the group of NSAIDs (DIC, IBU, and NAP) could be classified as baseline toxicants. Despite these differences in their predicted mode of toxic action, the applied mixture toxicity models (CA and IA) were generally in good agreement with the experimental data. However, as the CA model in general assumes the worst-case scenario, and gives overall closer predictions, it can be recommended also for modeling the mixture toxicity of dissimilarly acting pharmaceuticals. The presented results contribute to a better understanding of the risks posed by the presence of these chemicals in the environment.

Supplementary Information The online version contains supplementary material available at https://doi.org/10.1007/s11356-021-17928-y.

Acknowledgements We would like to thank the Center for Environmental Research and Sustainable Technology, University of Bremen, Germany, for cooperation in carrying out ecotoxicological research.

Author contribution AB-B: conceptualization, formal analysis, visualization, writing —original draft; ŁG: investigation; EM: formal analysis, visualization, writing — review and editing; AP: investigation, methodology; SS: resources, funding acquisition; PS: supervision, funding acquisition. The manuscript has been read and approved by all named authors.

Funding The financial support of the Polish National Science Center, under grant number: 2015/17/B/NZ8/02481.

Data availability Data associated with the present study can be accessed on request to the author (ewa.mulkiewicz@ug.edu.pl).

\section{Declarations}

Ethics approval and consent to participate Not applicable.

Consent for publication Not applicable.

Competing interests The authors declare no competing interests.

Open Access This article is licensed under a Creative Commons Attribution 4.0 International License, which permits use, sharing, 
adaptation, distribution and reproduction in any medium or format, as long as you give appropriate credit to the original author(s) and the source, provide a link to the Creative Commons licence, and indicate if changes were made. The images or other third party material in this article are included in the article's Creative Commons licence, unless indicated otherwise in a credit line to the material. If material is not included in the article's Creative Commons licence and your intended use is not permitted by statutory regulation or exceeds the permitted use, you will need to obtain permission directly from the copyright holder. To view a copy of this licence, visit http://creativecommons. org/licenses/by/4.0/.

\section{References}

Affek K, Załęska-Radziwiłł M, Doskocz N, Dębek K (2018) Mixture toxicity of pharmaceuticals present in wastewater to aquatic organisms. Desalin Water Treat 117:15-20. https://doi.org/10. 5004/dwt.2018.21964

Altenburger R (2003) Mixture toxicity and its modeling by quantitative structure-activity relationships. Environ Toxicol Chem 22:19001915. https://doi.org/10.1897/01-386

Altenburger R, Walter H, Grote M (2004) What contributes to the combined effect of a complex mixture? Environ Sci Technol 38(23):6353-6362. https://doi.org/10.1021/es049528k

Ankley GT, Brooks BW, Huggett DB, Sumpter JP (2007) Repeating history: pharmaceuticals in the environment. Environ Sci Technol 41:8211-8217. https://doi.org/10.1021/es072658j

Backhaus T (2016) Environmental risk assessment of pharmaceutical mixtures: demands, gaps and possible bridges. AAPS J 18:804813. https://doi.org/10.1208/s12248-016-9907-0

Backhaus T, Altenburger R, Boedeker W, Faust M, Scholze M, Grimme LH (2000) Predictability of the toxicity of multiple mixtures of dissimilarly acting chemicals to Vibrio fischeri. Environ Toxicol Chem 19(9):2348-2356. https://doi.org/10. 1002/etc.5620190927

Backhaus T, Faust M (2012) Predictive environmental risk assessment of chemical mixtures: a conceptual framework. Environ Sci Technol 46:2564-2573. https://doi.org/10.1021/es2034125

Brausch JM, Connors KA, Brooks BW, Rand GM (2012) Human pharmaceuticals in the aquatic environment: a review of recent toxicological studies and considerations for toxicity testing. Rev Environ Contam Toxicol 218:1-99. https://doi.org/10.1007/ 978-1-4614-3137-4_1

Aus der Beek T, Weber F-A, Bergmann A, Hickmann S, Ebert I, Arne Hein A, Küster A (2016) Pharmaceuticals in the environmentglobal occurrences and perspectives. Environ Toxicol Chem 35:823-835. https://doi.org/10.1002/etc.3339

Belden JB, Gilliom RJ, Lydy MJ (2007) How well can we predict the toxicity of pesticide mixtures to aquatic life? Integr Environ Assess Manag 3:364-372. https://doi.org/10.1002/ieam.56300 30307

Bopp S; Berggren E; Kienzler A; Van Der Linden S; Worth A. Scientific methodologies for the assessment of combined effects of chemicals - a survey and literature review. EUR 27471. Luxembourg (Luxembourg): Publications Office of the European Union; 2015. JRC97522. https://doi.org/10.2788/093511

Brain RA, Johnson DJ, Richards SM, Hanson ML, Sanderson H, Lam MW, Young C, Mabury SA, Sibley PK, Solomon KR (2004) Microcosm evaluation of the effects of an eight pharmaceutical mixture to the aquatic macrophytes Lemna gibba and Myriophyllum sibiricum. Aquat Toxicol 70:23-40. https://doi.org/10.1016/j. aquatox.2004.06.011
Caban M, Stepnowski P (2021) How to decrease pharmaceuticals in the environment? A review. Environ Chem Lett 19:3115-3138. https://doi.org/10.1007/s10311-021-01194-y

CHMP (2006) Committee for Medical Products for Human Use, Guideline on the Environmental Risk Assessment of Medical Products for Human Use, EMEA/CHMP/SWP/4447/00 corr.2, London. https://www.ema.europa.eu/en/documents/scientific-guideline/ guideline-environmental-risk-assessment-medicinal-productshuman-use-first-version_en.pdf

Cleuvers M (2003) Aquatic ecotoxicity of pharmaceuticals including the assessment of combination effects. Toxicol Lett 142:185-194. https://doi.org/10.1016/S0378-4274(03)00068-7

Cleuvers M (2004) Mixture toxicity of the anti-inflamatory drugs diclofenac, ibuprofen, naproxen and acetylsalicylic acid. Ecotoxicol Environ Safety 59:309-315. https://doi.org/10.1016/S01476513(03)00141-6

CVMP (2008) Committee for Medical Products for Veterinary Use, Revised Guideline on the Environmental Risk Assessment for Veterinary Medicinal Products in Support of the VICH GL6 and GL 38, EMEA/CVMP/ERA/418282/2005-Rev.1 Corr.1, London. https://www.ema.europa.eu/en/documents/scientific-guideline/ guideline-environmental-impact-assessment-veterinary-medic inal-products-support-vich-guidelines-gl6_en.pdf

De Liguoro M, Di Leva V, Gallina G, Faccio E, Pinto G, Pollio A (2010) Evaluation of the aquatic toxicity of two veterinary sulfonamides using five test organisms. Chemosphere 81:788-793. https://doi.org/10.1016/j.chemosphere.2010.07.003

De Liguoro M, Fioretto B, Poltronieri C, Gallina G (2009) The toxicity of sulfamethazine to Daphnia magna and its additivity to other veterinary sulfonamides and trimethoprim. Chemosphere 75:1519-1524. https://doi.org/10.1016/j.chemosphere.2009.02. 002

Di Nica V, Villa S, Finizio A (2017) Toxicity of individual pharmaceuticals and their mixtures to Aliivibrio fischeri: experimental results for single compounds and considerations of their mechanisms of action and potential acute effects on aquatic organisms. Environ Toxicol Chem 36:807-814. https://doi.org/10.1002/etc. 3568

Drzymała J, Kalka J (2020) Ecotoxic interactions between pharmaceuticals in mixtures: diclofenac and sulfamethoxazole. Chemosphere 259:127407. https://doi.org/10.1016/j.chemosphere.2020.127407

Dusi E, Rybicki M, Jungmann D (2019) The database "Pharmaceuticals in the environment" - update and new analysis -final report, German Bundesamt, TEXTE 67/2019. https://www.umweltbund esamt.de/sites/default/files/medien/1410/publikationen/2019-0624_texte_67-2019_database_pharmaceuticals-environment_0.pdf

Eguchi K, Nagase H, Ozawa M, Endoh YS, Goto K, Hirata K, Miyamoto K, Yoshimura H (2004) Evaluation of antimicrobial agents for veterinary use in the ecotoxicity test using microalgae. Chemosphere 57:1733-1738. https://doi.org/10.1016/j.chemosphere. 2004.07.017

Escher BI, Abagyan R, Embry M, Klüver RAD, Zarfl C, Parkerton TF (2020) Recommendations for improving methods and models for aquatic hazard assessment of ionizable organic chemicals. Environ Toxicol Chem 39:269-286. https://doi.org/10.1002/etc.4602

Escher BI, Baumer A, Bittermann K, Henneberger L, König M, Kühnert C, Klüver N (2017) General baseline toxicity QSAR for nonpolar, polar and ionisable chemicals and their mixtures in the bioluminescence inhibition assay with Alliivibrio fischeri. Environ Sci Process Impacts 19:414-428. https://doi.org/10.1039/C6EM0 0692B

Escher BI, Baumgartner R, Koller M, Treyer K, Lienert J, McArdell CS (2011) Environmental toxicology and risk assessment of pharmaceuticals from hospital wastewater. Water Res 45:75-92. https:// doi.org/10.1016/j.watres.2010.08.019 
Escher BI, Bramaz N, Richter M, Lienert J (2006) Comparative ecotoxicological hazard assessment of beta-blockers and their human metabolites using a mode of action based test battery and a QSAR approach. Environ Sci Technol 40:7402-7408. https://doi.org/10. $1021 / \mathrm{es} 052572 \mathrm{v}$

European Commission (1993) Commission Directive 93/67/EEC of 20 July 1993 laying down the principles for assessment of risks to man and the environment of substances notified in accordance with Council Directive 67/548/EEC. https://op.europa.eu/ en/publication-detail/-/publication/1b5257d9-fe8c-4071-9c79d0b9a8079b8b

Geiger E, Hornek-Gausterer R, Saçan MT (2016) Single and mixture toxicity of pharmaceuticals and chlorophenols to freshwater algae Chlorella vulgaris. Ecotoxicol Environ Saf 129:189-198. https:// doi.org/10.1016/j.ecoenv.2016.03.032

Godoy AA, Kummrov F (2017) What do we know about the ecotoxicology of pharmaceutical and personal care product mixtures? A critical review. Crit Rev Environ Sci Technol 47:1453-1496. https://doi.org/10.1080/10643389.2017.1370991

Godoy AA, Caloto de Oliveira A, Silva JGM, de Jesus Azevedo CC, Domingues I, Nogueira AJA, Kummrow F (2019) Single and mixture toxicity of four pharmaceuticals of environmental concern to aquatic organisms, including a behavioral assessment. Chemosphere 235:373-382. https://doi.org/10.1016/j.chemosphere. 2019.06.200

Grabarczyk Ł, Mulkiewicz E, Stolte S, Puckowski A, Pazda M, Stepnowski P, Białk-Bielińska A (2020) Ecotoxicity screening evaluation of selected pharmaceuticals and their transformation products towards various organisms. Environ Sci Pollut Res. https://doi.org/ 10.1007/s11356-020-08881-3

Hermens J, Leeuwangh P (1982) Joint toxicity of mixtures of 8 and 24 chemicals to the guppy (Poecilia reticulata). Ecotoxicol Environ Saf 6:302-310. https://doi.org/10.1016/0147-6513(82)90020-3

ISO 11348-3:2007(en) (2007) Water quality - Determination of the inhibitory effect of water samples on the light emission of Vibrio fischeri (Luminescent bacteria test) - Part 3: Method using freezedried bacteria. https://www.iso.org/obp/ui/\#iso:std:40518:en

Jacob RS, de Souza Santos LV, d'Auriol M, Lebron YAR, Moreira VR, Lange LC et al (2020) Diazepam, metformin, omeprazole and simvastatin: a full discussion of individual and mixture acute toxicity. Ecotoxicology 29:1062-1071. https://doi.org/10.1007/ s10646-020-02239-8

Kidd KA, Blanchfield PJ, Mills KH, Palace VP, Evans RE, Lazorchak JM, Flick RW (2007) Collapse of a fish population after exposure to a synthetic estrogen. Proc Natl Acad Sci USA 104(21):88978901. https://doi.org/10.1073/pnas.0609568104

Klatte S, Schaefer H-C, Hempel M (2017) Pharmaceuticals in the environment - a short review on options to minimize the exposure of humans, animals and ecosystems. Sustain Chem Pharm 5:61-66. https://doi.org/10.1016/j.scp.2016.07.001

Kortenkamp A., Backhaus T., Faust M., 2009. State of the art on mixture toxicity. Report. Available at: https://ec.europa.eu/envir onment/chemicals/effects/pdf/report_mixture_toxicity.pdf

Kümmerer K (2010) Pharmaceuticals in the Environment. Annu Rev Environ Resour 35(1):57-75. https://doi.org/10.1146/annurevenviron-052809-161223

Markovic M, Neale PA, Nidumolu B, Kumar A (2021) Combined toxicity of therapeutic pharmaceuticals to duckweed. Lemna Minor Ecotoxicol Environ Saf 208:111428. https://doi.org/10.1016/j. ecoenv.2020.111428

Neale PA, Leusch FDL, Beate I, Escher BI (2017) Applying mixture toxicity modelling to predict bacterial bioluminescence inhibition by non-specifically acting pharmaceuticals and specifically acting antibiotics. Chemosphere 176:387-394. https://doi.org/10.1016/j. chemosphere.2017.01.018
Neuwoehner J, Fenner K, Escher BI (2009) Physiological modes of action of fluoxetine and its human metabolites in algae. Environ Sci Technol 43:6830-6837. https://doi.org/10.1021/es9005493

OECD 202 (2004) Daphnia sp., acute immobilisation test. 1-12. https:// doi.org/10.1787/9789264069947-en

OECD 221 (2006) Lemna sp., growth inhibition test. 1-22. https://doi. org/10.1787/9789264016194-en

Pereira A, Silva L, Laranjeiro C, Lino C, Pena A (2020) Selected pharmaceuticals in different aquatic compartments: Part II-Toxicity and environmental risk assessment. Molecules 25(8):1796. https:// doi.org/10.3390/molecules25081796

Phyu YL, Palmer CG, Warne MS, Hose GC, Chapman JC, Lim RP (2011) A comparison of mixture toxicity assessment: examining the chronic toxicity of atrazine, permethrin and chlorothalonil in mixtures to Ceriodaphnia cf. dubia. Chemosphere 85:1568-1573. https://doi.org/10.1016/j.chemosphere.2011.07.061

R Core Team (2014) The R Foundation for Statistical Computing. Version $3: 3$

Rodriguez-Mozaz S, Weinberg HS (2010) Meeting report: pharmaceuticals in water-an interdisciplinary approach to a public health challenge. Environ Health Perspect 118:1016-1020. https://doi. org/10.1289/ehp.0901532

Schmitt H., Boucard T., Garric J., Jensen J., Parrott J., Péry A., Römbke J., Straub JO., Hutchinson TH., Sánchez-Argüello P., Wennmalm $\AA$ A., Duis K., 2010. Recommendations on the Environmental Risk Assesment of Pharmaceuticals - effect characterization. Integrated Environmental Assessment and Management 6, 588-602. https://doi.org/10.1897/IEAM_2009-053.1

Tang JYM, McCarty S, Glenn E, Neale PA, Warne MSJ, Escher BI (2013) Mixture effects of organic micropollutants present in water: towards the development of effect-based water quality trigger values for baseline toxicity. Water Res 47:3300-3314. https:// doi.org/10.1016/j.watres.2013.03.011

Tarazona JV, Escher BI, Giltrow E, Sumpter J, Knacker T (2010) Targeting the environmental risk assessment of pharmaceuticals: fact and fantasies. Int Environ Assess Management 6:603-613. https:// doi.org/10.1897/IEAM_2009-052.1

Ukić Š, Sigurnjaka M, Cvetnića M, Markića M, Novak SM, Rogošića M, Rasulevb B (2019) Toxicity of pharmaceuticals in binary mixtures: assessment by additive and non-additive toxicity models. Ecotoxicol Environ Saf 185:109696. https://doi.org/10.1016/j. ecoenv.2019.109696

Vaes WHJ, Urrestarazu-Ramos E, Hamwick C, van Holstein I, Blaauboer BJ, Seinen W, Verhaar HJM, Hermens JLM (1997) Solid phase microextraction as a tool to determine membrane/water partition coefficients and bioavailable concentrations in in-vitro systems. Chem Res Toxicol 10:1067-1072. https://doi.org/10. 1021/tx970109t

van Wezel AP, Opperhuizen A (1995) Narcosis due to environmental pollutants in aquatic organisms: Residue-based toxicity, mechanisms, and membrane burdens. Crit Rev Toxicol 25:255-279. https://doi.org/10.3109/10408449509089890

Vasilachi IC, Asiminicesei DM, Fertu DI, Gavrilescu M (2021) Occurrence and fate of emerging pollutants in water environment and options for their removal. Water 13(2):181-215. https://doi.org/ $10.3390 / \mathrm{w} 13020181$

Verhaar HJM, Van Leeuwen CJ, Hermens JLM (1992) Classifying environmental pollutants. 1 . Structure-activity relationships for prediction of aquatic toxicity. Chemosphere 25:471-491. https:// doi.org/10.1016/0045-6535(92)90280-5

VICH (2000) International Cooperation on Harmonization of Technical Requirements for Registration of Veterinary Medical Products, Guideline GL 6 on Environmental Impact Assessment (EIAs) for Veterinary Medicinal Products - Phase I, CVMP/VICH/592/98FINAL, London. https://www.ema.europa.eu/en/documents/scien 
tific-guideline/vich-g16-environmental-impact-assessment-eiasveterinary-medicinal-products-phase-i-step-7_en.pdf

VICH (2005) International Cooperation on Harmonization of Technical Requirements for Registration of Veterinary Medical Products, Guideline GL 38 on Environmental Impact Assessment for Veterinary Medicinal Products - Phase II, CVMP/VICH/790/03FINAL, London. https://www.ema.europa.eu/en/documents/scien tific-guideline/vich-gl38-environmental-impact-assessments-veter inary-medicinal-products-vmps-phase-ii_en.pdf

Watanabe H, Tamura I, Abe R, Takanobu H, Nakamura A, Suzuki T, Hirose A, Nishimura T, Tatarazako N (2016) Chronic toxicity of an environmentally relevant mixture of pharmaceuticals to three aquatic organisms (alga, daphnid, and fish). Environ Toxicol Chem 35:996-1006. https://doi.org/10.1002/etc.3285
Zou X, Lin Z, Deng Z, Yin D, Zhang Y (2012) The joint effects of sulfonamides and their potentiator on Photobacterium phosphoreum: Differences between the acute and chronic mixture toxicity mechanisms. Chemosphere 86:30-35. https://doi.org/10.1016/j. chemosphere.2011.08.046

Zrnčić M, Gros M, Babić S, Kaštelan-Macan M, Barcelo D, Petrović M (2014) Analysis of anthelmintics in surface water by ultra-high performance liquid chromatography coupled to quadrupole linear ion trap tandem mass spectrometry. Chemosphere 99:224-232. https://doi.org/10.1016/j.chemosphere.2013.10.091

Publisher's note Springer Nature remains neutral with regard to jurisdictional claims in published maps and institutional affiliations. 